\title{
Health and Welfare Services for the Aged
}

\author{
ALBERT L. CHAPMAN, M.D.
}

$A^{S}$ $\mathrm{S}$ AGE progresses, tissues tend to dry out and the skin tends to wrinkle; cells atrophy and degenerate; the metabolic rate is lowered ; reaction time decreases; and the repair of damaged tissues is slowed up. But the aging process proceeds at a slow pace in most people. It is particularly retarded in those who live moderately and plough back into their lives some of the profits of healthful living.

Excesses of drinking, eating, smoking, and worry, too little sleep, exercise, and relaxationthese are the tubercle and diphtheria bacilli, the streptococci and staphylococci of old age. These are the factors that invite premature degeneration of the mind and body. Yet these are the very factors over which everyone has considerable personal control.

A second characteristic of older people is poverty. Eighty percent of those over 65 have a cash income of less than $\$ 2,000$ a year; 60 percent have less than $\$ 1,000$ a year.

And the incidence of chronic illness, as one would expect, rises rapidly with age. That is why older people use hospitals more frequently than younger people and go to physicians more often. This compounds the economic plight of oldsters. In the last decade the rise in the cost of hospital and medical care has outstripped even the rapid rise in the overall cost of living.

\section{Characteristics of Long-Term Illness}

The chronic diseases, often called long-term illnesses, are different in many ways from the acute infectious diseases which have been brought under substantial control since 1900 . But two outstanding differences have a distinct bearing on the problem we are now considering.
First, the chronic illnesses are characterized by a long latent period when the existence of disease usually is unknown to its victim. However, this is the period when screening procedures, in many instances, can unmask the disease so that physicians may initiate treatment early.

The second difference is that chronic diseases are characterized by their chronicity. To be specific, if a 35-year-old woman is found to have diabetes or heart disease, she must learn to accept the fact that she will have the disease until she dies. This does not mean that she will be sick the rest of her life. She may, and usually does, live a fairly normal life. That will depend to a great extent on her willingness to face up to reality, to accept the fact that she will need continued medical supervision throughout life and that she will have to live within the limits imposed by her disease.

\section{Preventive Approaches}

There are four approaches to the prevention of disability and premature deaths from chronic illness which, in a sense, are time oriented.

The first of these I call "preventive living." This term is derived from that familiar phrase "preventive maintenance" so often applied to the care of equipment in order to extend its period of usefulness.

All of us have weak links in our chain of

Dr. Chapman is Assistant Surgeon General and chief of the Division of Special Health Services, Public Health Service. The paper is based on an address to the Virginia Council on Social Welfare at Roanoke, April 27, 1960. 
life, weak links with which we are born and which we have inherited. Therefore, we are more susceptible to one type of disease than another. One person may be prone to develop high blood pressure, another diabetes, and another rheumatic heart disease.

It is important, therefore, to make it a practice to go to a physician at periodic intervals throughout life so that he may have the opportunity of detecting these weak links as early as possible. As ideal as an annual physical examination sounds, it would be impractical for everyone to have a physical examination every year. There wouldn't be enough doctors to go around. However, a thorough checkup every 5 years before age 40, a 3-year checkup from 40 to 60 , and an annual checkup thereafter would go a long way toward keeping everyone fit and cutting down hospital and medical bills. Physicians would see more patients, but they would see each patient less often.

Certain habits are harmful to everyone regardless of the nature of the weak links in the individual's chain of life. Obesity has been strongly indicted as a precursor to many chronic diseases. With the increasing popularity of alcoholic beverages and their more widespread acceptance as social trappings, the incidence of alcoholism is increasing and with it cirrhosis of the liver. Heavy smoking as well as air pollution has been linked with an alarming increase in lung cancer. Peptic ulcers are said to affect 10 percent of the American people at some time in their life. Worry, emotional stress, bad eating habits, lack of sleep, all these are suspect. Hypertension has been linked with living habits as well as heredity.

The list of correlations between specific chronic disease states and immoderate living is almost endless. That is why I place so much emphasis on the importance of preventive living, particularly during adult life. At a time when science has not yet determined the specific causes of heart disease, cancer, strokes, or high blood pressure, people must learn to help themselves. There is a limit to what the doctor or the health officer can do for them.

The growing appreciation of the need for periodic health examinations and the increasing number of older people places a heavy demand on the time of overworked private physicians. Unfortunately as the demand for preventive health examinations grows, the number of physicians per thousand people is decreasing. To take up some of the slack, more screening examinations are being done, not to substitute for comprehensive physical examinations performed by physicians but to supplement them.

Only a limited number of diseases and conditions can be detected by screening examinations, but, in a growing number of States and localities, these examinations are sending thousands of people who had no idea they had a chronic illness to physicians for diagnosis and treatment.

\section{Care and Rehabilitation}

The lack of financial resources of most old people, the chronicity of their ailments, and their natural preference for care at home have been documented over the years. As a result, growing importance has been attached to the development of methods that will make it possible to take health services to old people in their own homes. For example, more and more local health departments are providing bedside nursing services, and in Person County, N.C., and in many large cities the value of home care programs has been demonstrated. The newly recognized category of homemaker is being grafted into health and welfare teams in a growing number of communities.

Through the efforts of the American Nursing Home Association and other interested groups the quality as well as the quantity of nursing homes is being raised year by year. If adequate financial support is provided for the care of guests in nursing homes, reasonable and humane minimum standards of care can be developed. But in many States, welfare payments are not sufficient to meet the costs.

The mounting toll of needless disability among the aged caused by strokes, arthritis, and fractures has focused the attention of medical and public health workers on the need for more extensive early rehabilitation services. Many of the permanent disabilities among older people should never occur. These disabilities which keep many old people from working and from caring for themselves could be prevented 
if early rehabilitation services were made available. Private physicians with the assistance of public health nurses and physiotherapists, where they are locally available, are now providing disabled patients with rehabilitation services in their own homes with a considerable degree of success.

\section{Fiscal Considerations}

In considering how to pay for the many new types of health services that will be required by the aging population, it may be well, in deference to accepted patterns of providing medical care, to discuss the care of indigents and nonindigents separately. About 60 percent of people over 65 are now receiving old-age and survivors insurance benefits, and an additional 10 percent are dependent upon public assistance.

These people, with such limited incomes, can pay for needed health services only with great difficulty if at all. Very few of them are included in the one-third of the "over 65" population able to purchase voluntary health insurance. As time goes on, a larger percentage of old people probably will be enrolled in voluntary health insurance plans, and the percentage of those who will be covered by private pension plans, in addition to OASI, will increase significantly.

It is even conceivable that public opinion will evolve to the point where retirement income will be set at approximately the level of peak individual income. In other words, old people will not be penalized for simply growing old. One of the commonest fallacies extant today is the belief that old people don't need money. This belief, in my opinion, represents selfish rationalization on the part of adults who have no desire to share their income with the aged. It may be seen then that we can look for a gradual improvement in the ability of old people to purchase the health services they need, but the problem in no way will be solved in this fashion.

One service that can be provided without violating present concepts of medical care is the supplementation of health services to indigent ill persons by State and local health and welfare departments working cooperatively with private physicians. State and local health depart- ments should and must become much more deeply involved in the administration of existing medical care plans for indigent ill persons. The belief that to do so might incur the misunderstanding of the medical profession is no longer justifiable. Many health officers still parade this belief in order to avoid taking on additional and sometimes burdensome responsibilities.

State and local welfare departments must find ways to provide and finance more preventive types of health services for older people. More screening services for adults and aged could pay large welfare dividends. More rehabilitation services could increase the earning capacity of disabled indigents and decrease the need for providing them with costly personal care services. More home care services could lower the level of hospital bills for indigent ill persons.

Any improvement in health services for the indigent segment of the population will be reflected in an improvement in the quality of care given by private physicians, hospitals, and health departments to the nonindigent population. Good medical practices like good manners are contagious. State and local health departments can provide many ancillary health services if the need for such services is recognized by private physicians and if a willingness is shown to use them.

In supervising the care of old people with disease, strokes, diabetes, fractures, and arthritis, many supplemental services, badly needed by private patients, could be more economically provided by nonmedical persons. Nutritionists, nurses, physiotherapists, social workers, and technicians have skills and competencies which could be invaluable to overworked physicians who often labor singlehandedly. These skills, if added to local health or welfare department staffs, could be made available to assist private physicians in the care of their chronically ill patients. This could be done and has been done in such a way as not to abridge traditional doctor-patient relationships.

\section{Coordinated Community Care}

The growing sophistication of health services for the aged, the increasing complexity of 
community patterns for providing these services, and the multiplicity of agencies purveying them have combined to create an urgent need for a better coordination of community care services. In New York City more than 3,000 different agencies, official and nonofficial, provide health care. In one city of 500,000 recently studied, more than 500 health agencies were identified. Even in remote rural counties the number of agencies interested in the provision of health services rarely drops below 25. This too often means that agency services are provided in an uneconomical and ineffective fashion. Duplication is rife.

In several communities leadership has evolved. Agency representatives have met. Health needs have been identified. Health resources have been tabulated. Gaps in health services and facilities have been documented. In this way, the duplication and overlapping of health services is being reduced to a minimum.

The need for services is growing so rapidly and the resources are so relatively few, none can afford to be wasted. It matters less who takes the lead in stimulating the development of such a plan than that such a plan be developed. In one community, leadership may evolve from the medical society; in another, leadership may arise in welfare or health departments; or voluntary health agencies may take the lead.

Aging has moral, economic, health, and social facets. The fact that there is a problem of aging-is indeed fortunate, for it stems from the scientific successes which brought the dreaded infectious diseases under substantial control and which promise in the years ahead to ameliorate the ravages of such diseases as heart disease, cancer, and arthritis.

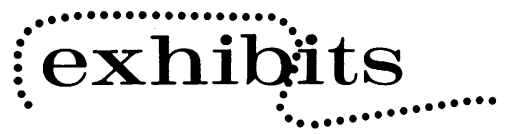

\section{Risk of Lung Cancer}

The risk of developing lung cancer according to the number of cigarettes smoked and the age of the smoker, as well as the lessened risk for the ex-smoker, is depicted in this exhibit. It features a thermometer with an accompanying pushbutton panel control box containing 12 buttons arranged according to number of cigarettes smoked and age group (55-59, 60-64, and $65+$ years). When a button is pressed, a column of lights in the thermometer reveals the death rate per 100,000 population for the appropriate category. The figures presented were derived from studies by Dorn, by Hammond and Horn, and by Doll and Hill.

Available on loan from the Cancer Control Branch, Division of Special Health Services, Public Health Service, Washington 25, D.C., the exhibit must be requested

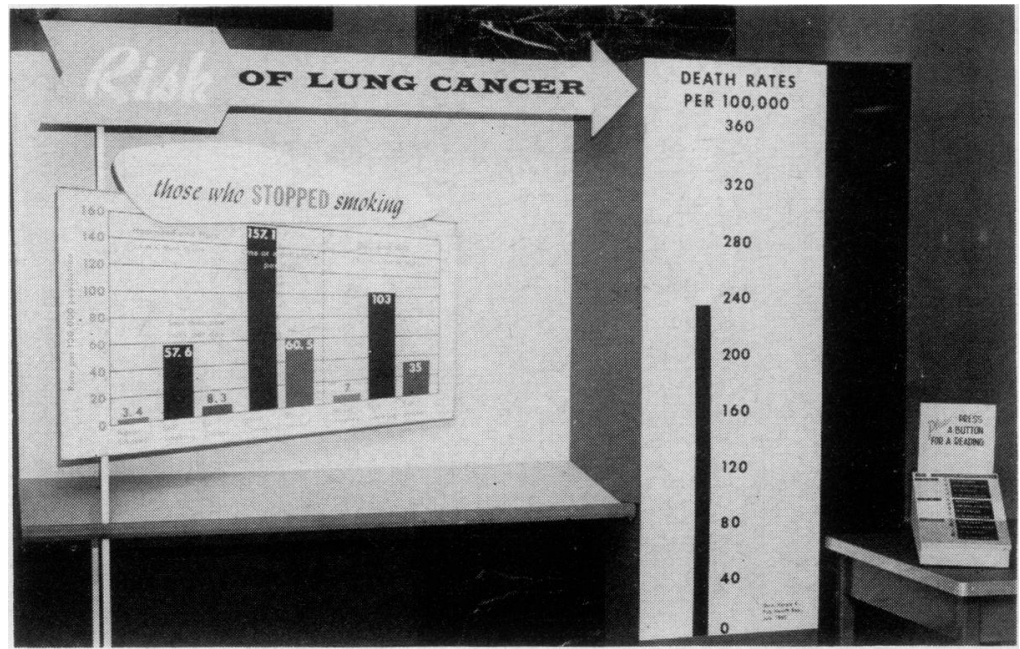

Specification: (No. CC-5.) A free-standing exhibit, 7 feet high and 8 feet wide, total weight 475 pounds including packing crates. Lighting fixtures require one 1,500-watt outlet. Column of lights is seen to best advantage when booth is 10 feet deep, or wide enough to prevent table on which the panel control box sits from interfering with spectator's view.

at least 1 month before the date desired. The branch will pay all costs of shipping and installing at large national and regional meetings, but for smaller meetings of primarily local interest these costs must be borne by the borrower. Instructions for assembling the exhibit are attached to the inside door of each of its two packing crates. It can be assembled by two men in 30 to 45 minutes. 